\title{
Mathematical Modeling of Intellectual Capital and Business Efficiency of Small and Medium Enterprises ${ }^{\dagger}$
}

\author{
Wadim Strielkowski ${ }^{1,2, * \mathbb{D}}$, Aida Guliyeva ${ }^{3}$, Ulviyya Rzayeva ${ }^{3,4, *}$, Elena Korneeva ${ }^{5,6}$ and Anna Sherstobitova ${ }^{6}$ \\ 1 Department of Agricultural and Resource Economics, University of California, Berkeley, CA 94720, USA \\ 2 Department of Trade and Finance, Faculty of Economics and Management, Czech University of Life \\ Sciences Prague, 16500 Prague, Czech Republic \\ 3 Department of Digital Technologies and Applied Informatics, Faculty of Technology and Design, \\ Azerbaijan State University of Economics, AZ1001 Baku, Azerbaijan; aida.guliyeva@sabah.edu.az \\ 4 Research Center of Digital Economy, Azerbaijan State University of Economics, AZ1001 Baku, Azerbaijan \\ 5 Department of Mass Communications and Media Business, Financial University under the Government of \\ the Russian Federation, Leningradsky Prospekt 49, 125993 Moscow, Russia; ENKorneeva@fa.ru or \\ e.korneeva@tltsu.ru \\ 6 Institute of Finance, Economics and Management, Togliatti State University, Belorusskaya Str. 14, \\ 445020 Togliatti, Russia; a.sherstobitova@tltsu.ru \\ * Correspondence: strielkowski@berkeley.edu or strielkowski@pef.czu.cz (W.S.); \\ ulviyya.rzayeva@unec.edu.az (U.R.) \\ + This paper is an extended and modified version of our paper published in the Proceedings of the 70th \\ International Scientific Conference on Economic and Social Development, Baku, Azerbaijan, 25-26 June 2021
}

Citation: Strielkowski, W.; Guliyeva,

A.; Rzayeva, U.; Korneeva, E.;

Sherstobitova, A. Mathematical

Modeling of Intellectual Capital and Business Efficiency of Small and Medium Enterprises. Mathematics 2021, 9, 2305. https://doi.org/ $10.3390 /$ math9182305

Academic Editor: Larissa Batrancea

Received: 26 July 2021

Accepted: 14 September 2021

Published: 18 September 2021

Publisher's Note: MDPI stays neutral with regard to jurisdictional claims in published maps and institutional affiliations.

Copyright: (c) 2021 by the authors. Licensee MDPI, Basel, Switzerland. This article is an open access article distributed under the terms and conditions of the Creative Commons Attribution (CC BY) license (https:// creativecommons.org/licenses/by/ $4.0 /)$.

\begin{abstract}
Our paper aims at testing the impact of separate elements of the intellectual capital (IC) represented for instance by the human, structural, and customer capital, on the functioning and performance of the small and medium-sized enterprises (SMEs) using mathematical modeling. We assess the intellectual capital with respect to the resource-based view theory. Our study is based on the data obtained from the 206 surveys with the representatives of small and medium-sized enterprises from Commonwealth of Independent States (CIS) countries. We employed a mathematical modeling approach as well as the SPSS application package in order to test our hypotheses about the influence of intellectual capital on the enterprise's efficiency. Our results helped us to determine that the concept of intellectual capital is practically not used in the management of small and medium-sized enterprises in CIS countries. It becomes apparent that individual techniques for managing intellectual resources can only be identified intuitively, based on an in-depth analysis of the current tasks facing managers. These findings confirmed the positive impact of intellectual capital on the performance of small and medium-sized enterprises in the conditions of the economies in transition represented hereinafter in our paper by CIS countries, but only with the availability of financial resources and with some important reservations.
\end{abstract}

Keywords: factor analysis; financial resources; intangible assets; small and medium enterprises; mathematical modeling

\section{Introduction}

The phenomenon of intellectual capital (IC) represents the key for achieving success in the modern global economy and thence calls for the need to be generated and employed effectively [1,2]. Nowadays, intellectual capital represents the assets that are indispensable for achieving competitiveness and shaping the strategy of any given company using such important elements as business culture, entrepreneurial experience, know-how, and information. Today, in the transition period experienced by the CIS economies, traditional management decisions, including the bureaucratic management approach, might not be sufficient for coping with the modern economic challenges [3-5]. Modern business 
reconstruction methods are often associated with the visualization, use, and assessment of the effectiveness of the intellectual capital concept [6].

In general terms, intellectual capital is all knowledge in an organization that has the potential to create value (while adhering to the mission, vision, and goals of the organization). Intellectual capital refers to the intangible type of capital owned by a company. Additionally, intellectual capital can be perceived as the intellectual value of an organization that predetermines its creative possibilities for the creation and implementation of intellectual and innovative products. All of this constitutes a great importance in the globalized and interconnected economy of the 21st century.

Intellectual capital includes the models, strategies, unique approaches, and psychological methodologies of an organization used in creating, competing, and solving problems. Knowledge, in turn, is an extremely important resource not only for organizations and countries in general but also for employees individually. Knowledge management, as part of intellectual capital, can provide an organization with entirely new ways to create a competitive advantage, acting as a competitive advantage themselves.

Within the context described above, small and medium-sized enterprises (SMEs) play a key role in the emergence and fostering of the economies of many developing countries. For these enterprises, the internal and external components of intellectual capital are crucial and frequently used in their day-to-day operation. However, the majority of domestic SMEs lack a systematic approach to managing and handling intellectual capital. The experience of both the developed and developing countries shows that the issues of using intellectual resources are of fundamental importance for increasing the efficiency of small and medium-sized businesses [7-9]. However, many research surveys do not pay enough attention to finding a configuration of intellectual resources that reflects their interaction during the transformation into the results of the company's activities $[10,11]$. Therefore, this work which focuses on identifying the direct and indirect impact of certain types of intellectual resources on the performance of SMEs represents a certain degree of scientific novelty.

Our paper examines the special manners of perceiving and managing intellectual capital by the company's leadership and determines the degree of intellectual capital influence on the performance of national SMEs.

The paper reveals the concept of intellectual capital and its components from the perspective of resource-based view theory. We employ the toolkit of factor analysis, an analysis of the influence of intellectual capital on increasing the competitiveness of a company in order to determine the nature of the relationship between the level of the firm's efficiency and the indicators of its intellectual capital. Based on established research, it has been founded that there exists a direct relationship between the level of developing the intellectual capital and the growth of SMEs' productivity. Furthermore, our calculations allow us to conclude that in formulating a set of measures for enhancing the effectiveness by using intellectual capital, it would be feasible to increase the knowledge and professional skills of the company's management team. It also analyses how intellectual capital is applied in SMEs and what factors impact its usage. This might be important for helping to shape governmental policies and strategies envisaged for increasing the efficiency of the intellectual capital. For instance, we identify the financial support of the process of increasing intellectual capital as one of the key factors affecting the efficiency of the company.

The body of this research adheres to the following generalized order: (1) Generating hypotheses. (2) Choice of dependent variables (performance indicators). (3) The choice of the measurement method as the basis for modeling intellectual capital and the determination of independent variables. (4) Testing our hypotheses using the statistical packages. (5) Analysis of the obtained results.

According to our previous findings, many similar studies have focused on intangible resources as the main factor for achieving competitiveness and profit generation in modern market conditions. The purpose of this study is the assessment of the degree of materiality of each IC component in the effectiveness of the organization's functioning. Furthermore, 
our paper aims at carrying out the statistical calculations with a purpose to reveal the ambiguous influence of the enterprise's financial resources on the change in the level of the IC components. All of the above makes this study an especially relevant and important research endeavor.

\section{Materials and Methods}

This work focuses on the strategic analysis of the organization's activities, and pays great attention to the organization-specific intellectual resources and competencies in the context of its competitive environment; although, as paradoxical as it may sound, in the transition economies of the Commonwealth of Independent States (CIS) countries, the intellectual resource is not always fundamental and mandatory, especially for SMEs.

The sampling and selection techniques used in this study were the following: using an electronic questionnaire prepared by the authors and sent to SMEs' managers, an initial collection of empirical data was carried out for subsequent analysis. The questionnaire was built from the point of view of the manager's psychology (for example, so that the manager would not, in any case, consider the questions asked as an encroachment on the internal space of the company). The questions raised took into account the specificity of the culture and practical experience of the interviewed audience: most of the SMEs in CIS countries are service organizations that have their own distinctive features, especially in the regions of the country. In the questionnaire, specific questions were placed at the beginning, and the general questions were located at the end. The full structure of the questionnaire is presented in Appendix A.

This study is based on the information about SMEs in CIS countries obtained through a questionnaire survey of the leaders (managers) of organizations. We used the electronic online questionnaires that were sent to the managers of SMEs selected using a quasirandom stratified sampling with a request to answer a number of questions on assessing the state of IC in their enterprise. This form of sampling used for this study constitutes a form of the stratified random sampling that takes each $\mathrm{n}^{\text {th }}$ entry (enterprise) from the available list of respondents [12].

We circulated a cover letter with our questionnaires which explained the anonymous and strictly confidential nature of the survey. Moreover, we stated that all our obtained results would be used only in the aggregated form and solely for research analysis. The questionnaires were filled out by choosing the numbers of the respective answers that most closely matched the respondent's opinion. A total of 600 forms were sent and 206 completed questionnaires were received which constitutes a $34 \%$ success rate. The descriptive statics of our sample is presented in Table 1.

Table 1. Data from a survey of SMEs' managers.

\begin{tabular}{ccc}
\hline Item & Number of Enterprises & Percentage \\
\hline Qualification of employees & & \\
\hline High school level & 81 & 39.3 \\
\hline Bachelor level & 92 & 44.6 \\
\hline Master's level & 20 & 9.7 \\
\hline Doctoral thesis level & 11 & 5.3 \\
\hline PhD level & 2 & 0.9 \\
\hline Economics field & & \\
\hline Industry & 12 & 5.8 \\
\hline Agriculture & 8 & 3.8 \\
\hline Services & 186 & 90.2 \\
\hline
\end{tabular}


Table 1. Cont.

\begin{tabular}{ccc}
\hline Item & Number of Enterprises & Percentage \\
\hline Enterprise size & & \\
\hline $10-20$ people & 96 & 46.6 \\
\hline $21-50$ people & 42 & 20.3 \\
\hline $51-100$ people & 40 & 19.4 \\
\hline $101-50$ people & 28 & 13.5 \\
\hline Age of the company & & 70.0 \\
\hline $1-10$ years & 144 & 27.1 \\
\hline $11-20$ years & 56 & 2.9 \\
\hline More than 20 years & 6 & \\
\hline Total & 206 &
\end{tabular}

Thence, the main value of this paper was the analysis of the influence of IC on increasing the competitiveness of the firm using the toolkit of factor analysis, the purpose of which was to concentrate the initial information. At the same time, we expressed a large number of the features under consideration (features that make up the very concept of IC) through a smaller number of more capacious internal characteristics of the phenomenon, which, unfortunately, could not be directly measured (for example, the performance of a firm was assessed by the head of the firm, and, naturally, we might encounter a large final statistical error, but we were forced to accept this estimate).

The factor analysis made it possible to track the stability of correlations between individual parameters (all types of IC, as well as all independent variables). It was the correlations between parameters, as well as between parameters and general factors that provided us with the basic diagnostic information about the processes. An interpretation of the identified factors was presented based on the meaning of the indicators characterizing these factors.

\section{Literature Review}

The research on the topic of intellectual capital in the modern sense and conditions is largely limited by the difficulty of its measuring and evaluating $[13,14]$. At the same time, many scientific studies mainly bind intellectual capital with intangible assets and the implementation of innovative potential $[15,16]$. However, this concept is very multifaceted, and empirical research needs to be studied for assessing the role of ICs in companies' performance. These studies include both theoretical analysis and empirical ones, including observation, model building, etc. Among the many scientific publications reviewed by the authors of this paper, the work of the Pakistani researcher Mohamed Khalique appeared to be particularly inspiring [17]. The aim of his paper was to assess the relationship of intellectual capital with the organizational performance of small and medium-sized enterprises operating in the electrical industry in Pakistan. Based on the results, it was noted that the independent variables of intellectual capital in the aggregate explain 54.6\% of the variation in the dependent variable, that is, the organizational performance of small and medium-sized enterprises. That is, indeed, the hypotheses about the positive influence of IC were confirmed. More recent papers on this matter covering SMEs in Pakistan as well as SMEs in China confirm these results and findings $[18,19]$.

Karl Haynes Leitners' work explored the relationship between intellectual capital and innovation. In the course of conducting multiple regression analysis, it was found that the influence of IC on innovation is about $70 \%$, but this is true to a greater extent for innovative companies. In addition, Leitner's results showed that structural capital did not have an impact in the long term and that SMEs with strong human capital could 
significantly develop their innovative activities [20]. Other recently published studies also corroborate Leitner's findings [21,22].

Cohen et al. [23] conducted a study to determine the role of intellectual capital in enterprise strategy during a financial crisis. It was found that during a crisis, relationships with the external environment and between employees play a more significant role than other components. Innovations and motivation could get low marks due to the lack of financial resources to maintain them. At the same time, even during a crisis, intellectual capital is considered a valuable resource, so enterprises should not refuse to finance it, because it can play a key role in strategy. These results are confirmed by similar recent studies [24,25].

There are also studies looking at understanding the essence of the concept of intellectual capital in general. One such study was carried out in New Zealand by Steenkamp and Kashyap [26]. They examined managers' perceptions of the impact of intangible assets on business success. The results showed that in most organizations there is no hierarchical division, and many respondents identified themselves with the managers of the organization, which indicates the small scale of the activities of firms and the limited resources. In addition, it was found that $83 \%$ are familiar with the concept of intellectual capital and mainly people divide IC into human, relational, and structural. Moreover, in the course of the survey, the researchers found that in most cases people associate intangible assets with the words such as "staff", "employees", "people" which emphasize the value of human capital for organizations.

All of the studies described above show that the role of the concept of intellectual capital in the conduct of business by companies should not be underestimated, since the ability of the economy to absorb knowledge and use it productively determines the economic strength of a nation and its well-being.

The analysis of all studies allows us to single out a number of general hypotheses, which were tested and confirmed in our work as well, based on the results of the econometric analysis of the data obtained:

1. There is a positive relationship between the level of intellectual capital and the company's efficiency.

2. On the developed markets, the impact of intellectual capital on a company's performance is more pronounced than in emerging markets.

3. There is a certain complementary relationship between the components of intellectual capital, which is expressed in mutual influence, the presence of a synergistic effect, as well as in the insignificance of certain elements (for example, the age or gender of the employee) without the presence of others.

\section{Factors Influencing the Use of Intellectual Capital in SMEs}

Currently, small and medium-sized businesses constitute an integral part of the economy in the most developed countries as they are performing the most important socioeconomic functions aimed at providing employment, creating a competitive environment, maintaining innovative activity, and alleviating social inequality. With regard to the above, in recent decades, technologically advanced and developing countries have been actively using tools to stimulate the use of intellectual capital in SMEs. When developing the measures aimed at increasing the efficiency of the use of intellectual capital, it is necessary to take into account the whole complex of factors affecting the process of its use. The study of features of developing the small and medium-sized businesses made it possible to propose a classification of factors affecting the process of using the country's intellectual capital:

1. Socio-economic factors:

- the quality of the country's labor resources (share of highly qualified personnel in the structure of labor resources) [27]; 
- the level of developing the scientific and educational complex in the country, including the tertiary education system (secondary vocational education, higher vocational education, as well as postgraduate education) [28];

- the efficiency in organizing internal and external migration processes of qualified labor resources [29];

- the share of high-tech industries in the country's economy capable of absorbing highly qualified personnel and creating results of intellectual activity [30].

2. Financial and economic factors:

- the standard of living in the country, that is, the presence of effective demand of consumers for goods and services created on the basis of using the intellectual capital [31];

- the level of consumers' education affecting their ability to use innovative high-tech goods and services [32];

- investment climate in the country, ensuring a sufficient level of investment demand for intellectual capital [33];

3. Administrative and legal factors:

- the quality of the legal framework governing relations in the scientific, technical and educational spheres [34];

- the level of legal protecting the results of intellectual activity [35];

- the presence of a functioning system in state regulation when using intellectual capital [36];

- the presence of a developed national innovation system, namely, an efficiently operating infrastructure that unites the scientific, educational, and industrial sectors, covering all regions and providing an unimpeded and efficient transfer of knowledge and innovative products and technologies (i.e., intellectual product) [37].

Thus, the effectiveness of developing entrepreneurship in the region is influenced by various groups of factors associated with the IC level at the enterprise. In connection with this, when assessing and justifying ways to increase the socio-economic efficiency of entrepreneurship development, it is necessary to take into account the impact of the presented factors.

\section{Modern Concept of Intellectual Capital and Its Structure}

At the present stage of the socio-economic development of the world economy and the economies of individual states, intellectual capital has acquired particular importance as contributing factor in production that affects the rate of economic growth. The level of the state's welfare system depends on the level of developing the social intellectual capital and on the efficiency of using its components in the country's economy.

Intellectual capital is considered a concept of accumulation and use of enterprise's intangible assets which are created using the human resources of the organization and various types of communication channels [38]. Understanding the importance of an intellectual resource for the effectiveness of an organization allows us to competently build a system of business processes and organize strategic planning.

The classic definition of intellectual capital was proposed by Stewart [39]: "Intellectual capital is knowledge that transforms raw materials and makes them more valuable, ... includes the talent of staff, the value of proprietary knowledge and processes, and the value of relationships with customers and suppliers". In order to paraphrase the author, we can just say that it constitutes the collective mental energy which is difficult to detect and even more difficult to manage.

The problem is that many researchers and managers give different meanings to the concept of intellectual capital. This happens for various reasons, including the lack of research in this area and the lack of physical fitness in the intellectual capital's components, which makes it difficult to measure them. To be able to manage intellectual capital, one should study its individual components and ways to manage them. Typically, researchers use a three-component structure of intellectual capital's concept which consists of human, structural, and relational capital [40]. Each component is considered both independently 
and in interaction with other subsystems which makes it possible to assess the impact of the IC concept on the performance of the company as a whole.

Human capital is considered to be one of the most important components of intellectual capital, as it represents the knowledge, skills, and abilities of the company's personnel [41]. Especially when it comes to enterprises that have severely limited material and financial resources, knowledge can create competitiveness for a product. Equally important is the fact that human capital plays a key role in innovation because it is the human who creates qualitatively new products that provide a company with a stable position among competitors in the market.

The second component of the IC concept is the structural capital which is the formalized results of the intellectual activity of an enterprise. This includes intellectual property, databases, various procedures related to business processes. We can say that this component characterizes the values that are transmitted in the structure and strategy of the organization. There is also research data in which structural capital is considered as an infrastructure for supporting human capital, that is, developing the potential of human knowledge [42]. It may also indicate that structural capital can influence investment in new products by attracting investors.

The third component of the IC concept is client capital. It is the external capital of the company, which includes relationships with all stakeholders in the organization that can be converted into value. Client capital creates a kind of network as an interaction between organizations and market resources [43]. It is important to note that client capital does not determine the processes of transferring knowledge or resources, but the degree of openness of the company, the level of its interaction with the external environment. The company's ability to competently build its relationships with stakeholders creates an opportunity to establish and maintain its competitiveness at all levels.

In all studies, there is a close connection between the components in their complementarity, the use of one component to enhance the impact of the other, which determines the consistency of the concept for achieving effectiveness.

\section{Assessment of Individual IC Components' Value Based on the Expenditures}

Currently, human capital is the most valuable resource both for an individual company and for society as a whole, much more important than natural resources or accumulated wealth [44]. It is human capital, and not factories, equipment, and production stocks that are today an indicator of competitiveness, economic growth, and efficiency [45]. To assess, form, and use human capital as the most important component of production, it is necessary to define it as an economic category. Thus, in a formalized form, the expression for quantifying human capital $H C$ will look like an additive model representing the sum of three components:

$$
H C=A+B+C
$$

where $A$-wage fund of an enterprise; $B$-enterprise expenditures on knowledge and skills capital; $C$-enterprise costs for "health capital". It should be borne in mind that each cost element has its own return. For example, the return on investment in human capital is higher than on investment in "health capital". Therefore, it is advisable to introduce the weighting coefficients of return $\beta_{1}, \beta_{2}, \beta_{3}$ for each type of cost.

$$
H C=\beta_{1} A+\beta_{2} B+\beta_{3} C
$$

where $\beta_{1}$-return on labor costs; $\beta_{2}$-return on costs of knowledge and skills capital; $\beta_{3}-$ return on "health capital" expenditures. The value of the coefficients is assigned based on the value of the return of each component to the human capital of the enterprise (in terms of return on financial capital). When determining the return on each type of cost, the most important factors should be considered:

- The "size" of the enterprise (scale of operations, type and level of developing the organizational structure, annual turnover); 
- the degree of labor "intellectualization", the level of knowledge-intensiveness of products;

- the "age" of the enterprise;

- availability of a personnel assessment and motivation system.

In addition, concepts such as the average level of education of workers in the enterprise and their average age affect the knowledge and skills capital and "health capital" of the company. The dependences of the efficiency of expenditures in human capital on the general level of education, costs for "health capital" on the average age of workers can be displayed through the parameters $\alpha_{1}$ and $\alpha_{2}$, respectively:

$$
H C=\beta_{1} A+\alpha_{1} \beta_{2} B+\alpha_{2} \beta_{3} C
$$

where $\alpha_{1}(2)$ and $\alpha_{2}$ (3)-parameters showing the dependence of the return on costs on the level of education and age, respectively,

$$
\alpha_{1}=\frac{\sum_{i=1}^{n} r_{i} z_{i}}{R z},
$$

where $r_{i}$ and $z_{i}$-the number of employees with the $i$-th level of education and their average salary; $n$ - the number of levels of education in a particular enterprise; $R$ - the total number of employees of the enterprise; $z$-average wages of workers. The function mapping the dependence of the return on the expenditures for "health capital" is as follows:

$$
\alpha_{2}=\gamma_{m} \sum_{j=1}^{n} k_{j} d_{j}+\gamma_{w} \sum_{j=1}^{n} k_{j} t_{j}
$$

where $\gamma_{m, w}$-the proportion of men and women, respectively, at the enterprise; $d_{j}, t_{j}$ share of male and female workers of the $j$-th age group; $n$-number of age groups; $k_{j}$ - the rate of return on investment in "health capital" depending on age groups, which are determined based on the retirement age. For workers of pre-retirement age, we take $k_{j}=1$, for workers of retirement age, but continuing to work at the enterprise, we take $k_{j}=0.85$.

Taking into account the specifics of the enterprises' activities, we assign the following coefficients of return: $\beta_{1}=0.7, \beta_{2}=0.25, \beta_{3}=0.05$ [30]. The values of the parameters $\alpha_{1}$, $\alpha_{2}$, calculated in accordance with (2) and (3), reflect the dependence of the return on costs on the level of education and age are $\alpha_{1}=0.95, \alpha_{2}=0.98$.

Structural capital exists in a variety of forms and manifests itself in different enterprises in different ways. Patents, inventions, descriptions of production processes, trademarks, copyrights have certain forms of their presentation, and also, in accordance with the feasibility study, have legally formalized valuation characteristics. Along with the listed intellectual funds, an enterprise may have other intellectual assets, intangible structural values that take less definite forms.

Structural capital (SC) is defined by the authors as the sum of the value of innovation capital formed by the organization $(\operatorname{Inn} C)$ and the company's total investment in process capital, representing the sum of the organization of production, management, and labor $(\operatorname{PrC})$ :

$$
S C=\operatorname{Inn} C+\operatorname{Pr} C
$$

where InnC - cost of innovation capital; $\operatorname{PrC}$-investment in process capital. The value of innovation capital is defined as the sum of the values of scientific activity and development, as well as the inventory value of the organization's intangible assets.

Client capital is capital that consists of connections and sustainable relationships with clients and consumers. One of the main goals of the formation of client capital is to create such a structure that allows the consumer (client) to productively communicate with the company's personnel. The client capital of the enterprise (also called the capital of relations) is characterized by qualities such as the depth (degree) of penetration, breadth (distribution), constancy, and confidence that consumers will continue to give preference 
only to this enterprise. The client capital of a company extends to its suppliers as well. It is much easier to account for. Brand fidelity, for example, is a form of client capital, for which there is a clear valuing methodology. This is achieved by calculating the premium that buyers are willing to pay for the branded product in preference to others. Client capital is created by adherents of the company's products, that is, its customers, clients. Clients' preferences are manifested in three ways: clients turn to services mainly only from "their" company; the business of the enterprise grows due to the share of its regular customers; the company's customers are impervious to the calls and promises of competitors (price tolerance). The greater the economic power of the customers and clients of the enterprise, the more client capital it has, since consumers, along with material assets, structural capital, and human capital, are the main wealth of the enterprise [46].

For the assessment of client capital (CC), the method proposed by Berger and Nasr was used-the BN approach [47]. This method is based on the following assumptions:

(1) customer retention costs are assumed annually, and the customer retention rate over time remains constant,

(2) sales of goods and services are annual,

(3) the profit received from the buyer remains unchanged during the entire period of cooperation with the company.

Based on these assumptions, the following relationship is used to calculate CC:

$$
C C=G C \times \sum_{i=1}^{n} \frac{r_{i}}{\left(1+d_{i}\right)}-M \times \sum_{i=1}^{n} \frac{r^{i-1}}{(1+d)^{i-0.5}},
$$

where $n$-number of years of SMEs' operation; $d$-annual discount rate; GC - annual profit received from the buyer; $M$-annual investment for customer retention; $r$-customer retention rate [48].

Data sources for further analysis and calculations are based on the information from the SME's managers (leaders) that is available from our electronic questionnaire (see Appendix A). The authors are forced to make a reservation that all data are approximate. Our calculations are shown in Table 2.

Table 2. Assessment of IC components.

\begin{tabular}{|c|c|c|c|c|}
\hline \multicolumn{5}{|c|}{ IC Components } \\
\hline \multicolumn{5}{|c|}{ Human capital HC } \\
\hline $\begin{array}{l}\text { Wage fund of enterprise ( } A, \\
\text { thousand manats) }\end{array}$ & $\begin{array}{r}\text { Enterprise costs for } \mathrm{k} \\
(B, \text { tho }\end{array}$ & $\begin{array}{l}\text { nowledge and skills capital } \\
\text { usand manat) }\end{array}$ & $\begin{array}{l}\text { Enterprise costs for } \\
\text { "health capital" ( } C \text {, } \\
\text { thousand manat) }\end{array}$ & $\begin{array}{c}\text { Human capital cost (HC, } \\
\text { thousand manat) }(1)\end{array}$ \\
\hline 15.864 & & 0.7932 & 3.1728 & 19.83 \\
\hline \multicolumn{5}{|c|}{ Structural capital SC } \\
\hline $\begin{array}{l}\text { Innovation capital ( } \operatorname{Inn} C, \\
\text { thousand manats) }\end{array}$ & \multicolumn{3}{|c|}{ Process capital ( $\operatorname{Pr} C$, thousand manats) } & \multirow{2}{*}{$\begin{array}{c}\text { Structural capital cost } \\
(S C, \text { thousand manats) }(4)\end{array}$} \\
\hline Intangible asset value & $\begin{array}{l}\text { Production } \\
\text { Organization }\end{array}$ & $\begin{array}{l}\text { Management } \\
\text { organization }\end{array}$ & Labor organization & \\
\hline 980.428 & 67,832 & 15,631 & 9.953 & 1073.844 \\
\hline \multicolumn{5}{|c|}{ Client Capital CC } \\
\hline Discount rate $(d, \%)$ & $\begin{array}{l}\text { Sales profit (GC, } \\
\text { thousand manats) }\end{array}$ & $\begin{array}{l}\text { Customer retention costs } \\
(M, \text { thousand manats })\end{array}$ & $\begin{array}{l}\text { Customer retention } \\
\text { rate }(r, \%)\end{array}$ & $\begin{array}{l}\text { Client capital cost (CC, } \\
\text { thousand manats) (5) }\end{array}$ \\
\hline 0.0417 & 5271.871 & 1704.857 & 0,9 & 2884.365624 \\
\hline
\end{tabular}

\section{Intellectual Capital and Efficiency of Small and Medium Businesses}

In a market economy, intangible resources are of particular importance in achieving the competitiveness of an enterprise and its strategic success, due to competitive advantages. 
Currently, there is a growing interest in research on the role and importance of intangible resources for achieving the strategic success of an enterprise in a market economy. This is explained by the general trends in world economic development: the intensification of international mergers and acquisitions of companies, the internationalization of financial markets, increased competition for leadership on a global scale, the expansion of the service sector, the acceleration and complication of scientific and technological development.

It needs to be understood that the competitiveness of a firm directly depends on the level of its capitalization, and it, in turn, is determined not so much by the cost of the property and economic complex as by the presence of intangible assets. Forming competitive advantages on the basis of intangible assets that cannot be copied, the entrepreneurial structure increases the capitalization of the business and extends the level of its competitiveness. The share of intangible assets in the company's value can become a benchmark for assessing the competitiveness of companies.

Since in this work IC is considered as the sum of components according to Stewart (human capital, structural capital, and client capital), we can formulate the following research hypotheses:

H1. Human capital significantly improves the efficiency of SMEs.

H2. Structural capital significantly improves the efficiency of SMEs.

H3. Client capital significantly improves the efficiency of SMEs.

\section{Influence of Financial Resources on Intellectual Capital Value}

Whatever the conventionally identified types of intellectual capital are, they somehow exist in close unity, which means that investments should be made in the development of intellectual capital as a whole, in all its varieties. The development of only one side of intellectual capital at the expense of others will not bring great benefits to the organization, but it may even be harmful.

In modern conditions, the growth in the value of commercial organizations is largely determined by the increase in intellectual capital. At the same time, accounting methods are of little use for an adequate assessment of intellectual capital. For example, accounting methods for valuing a trademark view it as an asset that loses its value as it is used, when in fact the value of trademark increases over time.

Patents and licenses are recorded in the accounting documents in accordance with the cost of their registration, and not their actual cost. In addition, there is an erroneous separation of investment and costs, for example, training and advertising costs are regarded as extra expenses, while in fact they are long-term investments.

In addition, a large amount of the organization's total capital never appears on the balance sheets at all-for example, customer relations, knowledge bases, staff qualifications.

Thus, the competitiveness of an organization directly depends on how fully and successfully it uses its intellectual capital and how actively it invests in its development. In this way, we put forward the following hypotheses:

H4. Financial resources strengthen the link between human capital and SME performance, so the association will be stronger when businesses have adequate financial resources.

H5. Financial resources strengthen the link between structural capital and SME performance, so the association will be stronger when businesses have adequate financial resources.

H6. Financial resources strengthen the link between client capital and SME performance, so the association will be stronger when businesses have adequate financial resources.

\section{Discussion}

\subsection{Variables Used in the Model}

This section describes the conceptual and operational definitions of the variables used in the study. 
Intellectual capital

As an independent variable, we will take the IC indicator. At the same time, it acts as a composite variable consisting of three components: human capital (HC), structural capital (SC), and client capital (CC).

Financial resources

Financial resources (FR) - it is cash at the disposal of the enterprise and intended to ensure its efficient operation, to meet financial obligations. In the aspect of the article, we are interested in financial resources as the main mechanism of economic incentives for employees.

Firm efficiency

The classic exit/entry formula for measuring the effectiveness of large companies does not work well for SMEs, as the financial transparency of small and medium-sized businesses leaves much to be desired. Therefore, in assessing the firm efficiency (FE), we preferred to accept the company's own assessment of the effectiveness expressed by the head of the company (respondent). Points were measured using a five-point Likert scale.

Control variables

A control variable is a variable which values do not change at different levels of the independent variable.

Company size (Size) has traditionally been included in studies as a control variable. This is logical, since the personnel management systems of a large and small organization are likely to differ in the degree of structuredness and differentiation of the respective functions [49]. The logarithm of the number of company employees at the time of the study was used as an indicator of the size.

The age of the company (Age) has a significant and opposite effect on the size of the financial cycle. It is expected that the older the firm, the more well-known it is in the market and the more stable relationships it has with buyers and suppliers, which leads to a shorter financial cycle. This is confirmed in research, for example, by Mathuva [50].

Qualified personnel are the most important asset and indisputable advantage of any organization. In this regard, the labor potential of the enterprise characterizes the level of education (Education) of workers [51].

In studies on economic efficiency, it is customary to include the industry affiliation of the enterprise as a control variable. In this case, we were forced to abandon this parameter due to the fact that we did not notice a significant difference between the groups "Industry", "Agriculture" and "Services".

However, we take the age and size of enterprises, as well as the qualifications of employees, as continuous controlled variables. Our empirical results show that the size of enterprises does not play a significant role, while the age of the companies and the level of education of the personnel strongly influence the analysis of hypotheses.

\subsection{Experimental Results}

\subsubsection{Descriptive Statistics}

For data analysis, we used the SPSS statistical data analysis package. For the first step, the mean and standard deviation were calculated, and the presence of multicollinearity and normality of the data was checked. Calculations show (Table 3) that the mean and standard deviation for human capital are 19.04 and 0.87 , respectively, for structural capital, client capital, financial resources, and efficiency, the values are $10.20(0.34), 2.81(0.05)$, $15.51(0.20)$ and $7.43(0.67)$, respectively. All standard deviations are small enough and demonstrate that the standard variation between each individual value and the arithmetic mean is within acceptable limits. The indices of asymmetry and kurtosis indicate that the distribution of data is normal, since they are in the permissible range of values of skewness and kurtosis $( \pm 2)$. The upper limit of the variance inflation factor (VIF) as a measure of multicollinearity is not more than 5 , the lower limit is not less than 0.1 . Therefore, 
there will be no strong correlation between the factors. Thus, we took the first step of our analysis - the presentation of descriptive statistics (Table 3).

Table 3. Descriptive statistics of the model's variables.

\begin{tabular}{cccccc}
\hline Variables & Means & Std. Dev. & Skewness & Kurtosis & VIF \\
\hline HC & 19.044 & 0.87170 & 0.665193 & 0.21514 & \\
\hline SC & 10.19696 & 0.343641 & -1.24792 & 1.2693 & 4.691438 \\
\hline CC & 2.810389 & 0.049608 & -1.88375 & 0.3519558 & 1.260705 \\
\hline FR & 15.51256 & 0.195375 & -0.50709 & -0.262651 & 2.849643 \\
\hline FE & 7.425776 & 0.464419 & 0.862212 & -0.17513 & 1.001213 \\
\hline
\end{tabular}

\subsubsection{Correlation between Variables}

Correlation relationships cannot be considered as evidence of a causal relationship, they only indicate that changes in one feature, as a rule, are accompanied by certain changes in another, but whether the cause of the changes is in one of the features or is it outside the studied pair of features, we don't really know.

The relationship between the variables is shown in Table 4. Based on the results of the correlation analysis, a conclusion can be made about the presence and nature of functional dependence or preference for describing the object under study of one type or another in the regression model.

Table 4. Values of the correlation between the variables.

\begin{tabular}{|c|c|c|c|c|c|c|c|c|}
\hline & Education & Size & Age & $\mathrm{HC}$ & SC & $\mathrm{CC}$ & FR & FE \\
\hline Education & 1 & & & & & & & \\
\hline Size & 0.595674 & 1 & & & & & & \\
\hline Age & 0.694371 & 0.9377 & 1 & & & & & \\
\hline $\mathrm{HC}$ & 0.87739 & 0.1774 & 0.3525 & 1 & & & & \\
\hline SC & 0.86487 & 0.4170 & 0.6843 & 0.8870 & 1 & & & \\
\hline $\mathrm{CC}$ & -0.50299 & 0.3880 & 0.3338 & 0.4547 & 0.8030 & 1 & & \\
\hline FR & 0.682843 & 0.4346 & 0.8202 & 0.8056 & 0.8000 & 0.4087 & 1 & \\
\hline FE & -0.29508 & 0.2361 & -0.373 & -0.035 & 0.2612 & 0.6689 & -0.70 & 1 \\
\hline
\end{tabular}

To optimize the calculations for computation the Pearson correlation coefficient, we used the analog obtained by using the following transformations:

$$
r_{x y}=\frac{n \times \sum\left(x_{i}-y_{i}\right)-\left(\sum x_{i} \times \sum y_{i}\right)}{\sqrt{n \times \sum x_{i}^{2}-\left(\sum x_{i}\right)^{2} \times n \times \sum y_{i}^{2}-\left(\sum y_{i}\right)^{2}}}
$$

where $n$-the number of our observations, $y_{i}$-dependent variables, $x_{i}$-independent variables.

Not all IC components have the same positive effect on a firm's efficiency: there is a small, but still negative correlation between efficiency and human capital (-0.035). In this case, this value is so close to 0 that we will assume that there is no correlation between HC and FE. According to calculations, the efficiency of SMEs is positively affected by the firm's client capital (0.67). This trend can be explained by the fact that a high customer retention rate $(90 \%)$ has a positive effect on the lifetime value of the customer and client capital, and thus on the firm efficiency.

On the other hand, we see a fairly high connection between the number of financial resources invested in the intellectual potential of the company, age (0.8202), human (0.8056), and structural (0.8) IC components. In addition, a remarkable relationship can be traced 
between education and human and structural capital (0.87739 and 0.86487, respectively), which is quite intuitively explicable. Since all values of the pair correlation coefficients in modulus are not higher than $0.6-0.7$, there is no threat of multicollinearity.

\subsubsection{Common Method Variance}

It is known that the e-survey method can influence the results for those who may not be familiar with the electronic interface, and in the case under consideration, common method variance may occur, that is, the cross-correlations between the factors may be overestimated or underestimated. There are several anticipated remedies that can help avoid or minimize possible deviations from conventional practices. We ran a Harman single factor test in SPSS to check if a single factor does not significantly load all elements (see Table 5).

Table 5. Harman single factor test.

\begin{tabular}{cccccc}
\hline \multirow{2}{*}{ Harman Single Factor Test } & Size & Age & HC & SC & CC \\
\cline { 2 - 6 } & $\mathbf{0 . 1 7}$ & $\mathbf{0 . 2 2 1}$ & $\mathbf{0 . 2 0 7}$ & $\mathbf{0 . 2 0 2}$ & $\mathbf{0 . 1 5 4}$ \\
\hline$t$-statistics & 1.82 & 2.01 & 2.003 & 1.55 & 0.987 \\
\hline Factor 1 & 0.554723 & 0.52574 & 0.52789 & 0.57132 & 0.581458 \\
\hline Factor 2 & 0.69154 & 0.70912 & 0.791048 & 0.60032 & 0.709107 \\
\hline
\end{tabular}

At values of 0.5 and higher, the set of variables for a given sample is considered unsuitable [52]. In our case, the specific weight of the single factor does not reach $23 \%$, which is quite acceptable. We can conclude that our sample is free from the common method variance.

\subsubsection{Possible Response Bias}

Respondents, when answering survey questions, may seek to leave a socially desirable perception about themselves (normative editing); in surveys, this trend may lead to an overstatement of participation in socially desirable activities and underestimation of participation in those considered undesirable. Respondents may deliberately try to distort the survey results, for example, by not being entirely accurate in describing the current state of the business or doing wishful thinking. They can also give quick and thoughtless responses to speed up the completion of the survey. To eliminate this kind of potential bias, we used the $t$-test to assess whether there is a bias in the data associated with this desire of the respondents. The test consisted of comparing the results of two groups of respondents: those who gave the answer immediately and those who delayed a little with the answer. The test results showed that, even with such a hypothetical bias, the answers did not distort the overall picture ( $p$-values of $t$-tests show numbers more than 0.05 ), so we will assume that there are no systematic errors.

\subsubsection{Reliability and Validity of Tests}

In order to find out how the developed test will correlate with other tests aimed at constructs that are in a theoretically known or supposed connection with the investigated ones, we will analyze the "assumed validity" of the presented methodology by means of factor analysis.

Test conducted by fitness categories-parsimonious fit (IFI, CFI, TLI, NFI), incremental fit (RMSEA, AGFI, GFI) and absolute fit (CMIN/Df). The coefficient CMIN/Df $=2.804$ guarantees the suitability of our model, the rest of the parameters GFI $=0.90, \mathrm{CFI}=0.95$, TLI $=0.94$, NFI (0.93) and RMSEA $=0.07$ correspond to acceptable results (Table 6). 
Table 6. Checking the reliability and validity of the tests.

\begin{tabular}{|c|c|c|c|c|c|}
\hline \multicolumn{6}{|c|}{ Global Quality Criteria } \\
\hline GFI $(\geq 0.90)$ & $0.90(0.90)$ & AGFI $(\geq 0.90)$ & $0.89(0.87)$ & NFI $(\geq 0.90)$ & $0.93(0.92)$ \\
\hline CFI $(\geq 0.90)$ & $0.95(0.94)$ & TLI $(\geq 0.90)$ & $0.94(0.93)$ & RMSEA $(\leq 0.08)$ & $0.07(0.08)$ \\
\hline \multicolumn{6}{|c|}{$\mathrm{CMIN} / \mathrm{Df}=2.804$} \\
\hline
\end{tabular}

Now, we conduct a confirmatory factor analysis (CFA) of the principal components.

The common form of the CFA model with $r$ features and $s$ methods can be shown using two sets of equations [53]

$$
\begin{gathered}
\mathrm{Y}=\left[\Lambda_{\mathrm{F}} \Lambda_{\mathrm{M}}\right]\left[\begin{array}{c}
\eta_{\mathrm{F}} \\
\eta_{\mathrm{M}}
\end{array}\right]+\mathcal{E}, \\
\mathrm{X}=\Lambda_{\mathrm{F}} \Psi_{\mathrm{F}} \Lambda_{\mathrm{F}}^{\prime}+\Lambda_{\mathrm{M}} \Psi_{\mathrm{M}} \Lambda_{\mathrm{M}}^{\prime}+\theta,
\end{gathered}
$$

where $\mathrm{Y}$-is the vector of $r s$ observed measures for $r$ features and $s$ methods, $\eta=\left[\eta_{\mathrm{F}} \eta_{\mathrm{M}}\right]$ is an $(r+s) \times 1$ vector of feature and method factors, $\mathcal{E}$ is a vector of $r s$ tailings for $\mathrm{Y}$. $\mathrm{X}$ is an $r s \times r s$ implied covariance matrix for $\mathrm{Y}, \Psi_{\mathrm{F}}$ is an $r \times r$ correlation matrix for traits, $\Psi_{\mathrm{M}}$ is an $s \times s$ correlation matrix for methods, $\theta$ is an $r s \times r s$ diagonal matrix of unique variance for $\mathcal{E}, \Lambda_{\mathrm{F}}=\left[\Lambda_{1}, \Lambda_{2}, \ldots, \Lambda_{\mathrm{s}}\right]^{\prime}, \Lambda_{\mathrm{j}}$ is an $r \times r$ diagonal matrix with trait factor loadings for the $r$ traits measured by the $j$-th method, and

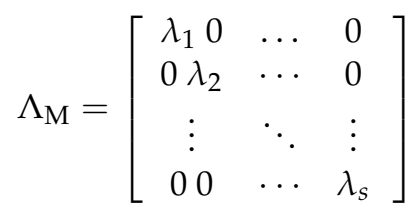

where $\lambda_{j}$ is an $r \times 1$ vector of factor loadings for the $j$-th method.

Application of the CFA model to data permits one to test for, and partial variance into, trait, method, and random error.

Consider the correlations between variables and two factors: one concerns firm efficiency, the second-financial resources (Table 7). Apparently, the first factor is more correlated with the variables than the second. This is to be expected because the factors are allocated sequentially and contain less and less total variance. Factor loadings give satisfactory values (AVE) for convergent confidence (above 0.50 ) and discriminant confidence (above 0.70 after calculating the square root AVE).

Table 7. Factor analysis of principal components.

\begin{tabular}{ccccc}
\hline Variables & Estimate & AVE & $\sqrt{\text { AVE }}$ & CR \\
\hline Human Capital & & 0.53134 & 0.728931 & 0.847594 \\
\hline hc5 & 0.75 & & & \\
\hline hc4 & 0.74 & & & \\
\hline hc3 & 0.56 & & & \\
\hline hc2 & 0.69 & & & \\
\hline hc1 & 0.87 & & & \\
\hline Structural Capital & & 0.5793 & 0.761118 & \\
\hline sc4 & 0.63 & & & \\
\hline sc3 & 0.89 & & & \\
\hline sc2 & 0.71 & & & \\
\hline sc1 & 0.79 & & & \\
\hline
\end{tabular}


Table 7. Cont.

\begin{tabular}{ccccc}
\hline Variables & Estimate & AVE & $\sqrt{\text { AVE }}$ & CR \\
\hline Customer Capital & & 0.51134 & 0.71508 & 0.879353 \\
\hline cc6 & 0.69 & & \\
\hline cc5 & 0.70 & & \\
\hline cc4 & 0.79 & & \\
\hline cc3 & 0.71 & & \\
\hline cc2 & 0.68 & & \\
\hline cc1 & 0.65 & & \\
\hline Financial Resources & & & & \\
\hline fr5 & 0.89 & & \\
\hline fr4 & 0.75 & & \\
\hline fr3 & 0.86 & & \\
\hline fr2 & 0.75 & & \\
\hline fr1 & 0.69 & & \\
\hline Firm Efficiency & & & \\
\hline fe6 & 0.765636 & \\
\hline fe5 & 0.78 & & \\
\hline fe4 & 0.78 & & \\
\hline fe3 & 0.79 & & \\
\hline fe2 & 0.77 & & \\
\hline fe1 & & & \\
\hline
\end{tabular}

To measure reliability or internal consistency, we used the Cronbach's alpha test:

$$
\alpha=\frac{N \cdot \bar{c}}{\bar{\vartheta}+(N-1) \cdot \bar{c}},
$$

where $N$-the number of items, $\bar{c}$-average covariance between item-pairs, $\bar{\vartheta}$-average variance.

The Composite Reliability (CR) score also gives an acceptable value (above 0.70).

\subsubsection{Hypotheses Testing}

Now we go directly to the hypotheses and their interpretation (Table 8). For this, we applied two tests: t-statistic and $F$-test. All $t$-statistics indicate the fulfillment of null hypotheses - there is no excess in absolute quantity of the critical value for this distribution. We conclude that control factors (staff education, size, and age of enterprises) play a significant role in the model. It should be addressed how many arguments will allow the null hypothesis to be rejected in favor of the alternative. The smaller the $p$-value, the stronger the arguments against the null hypothesis. Traditionally, it is believed that if $p<0.05,(=0.05)$, then there are enough arguments to reject the null hypothesis, although there is a small chance against this. Then you can reject the null hypothesis and say that the results are significant at the $5 \%$ level. In contrast, if $p>0.05$, then there are not enough arguments to reject the null hypothesis. In our particular case, the $p$-values are close to 0.5. This conclusion does not mean that the null hypothesis is true-there are simply not enough arguments to reject it.

The F-test is very important in regression analysis and is essentially a special case of constraint testing. If the value of this statistic is greater than the critical value at a given level of significance, then the null hypothesis is rejected, which means the statistical 
significance of the regression. Table 8 indicates the rejection of hypotheses 4 and 5 about the influence of financial resources on the level of intellectual capital of the enterprise. All our other inferences, in a sense, also confirm this conclusion.

Table 8. Results of the hypotheses testing.

\begin{tabular}{ccccc}
\hline Hypothesis & $\boldsymbol{t}$-Test & $\boldsymbol{F}$-Test & F-Value & $\boldsymbol{p}$-Value \\
\hline $\mathrm{H} 1(\mathrm{HC} \rightarrow \mathrm{FE})$ & 1.323223726 & 0.003639595 & 0.955687626 & 0.277571627 \\
\hline $\mathrm{H} 2(\mathrm{SC} \rightarrow \mathrm{FE})$ & 0.496989932 & 0.219745654 & 0.671194807 & 0.653335101 \\
\hline $\mathrm{H} 3(\mathrm{CC} \rightarrow \mathrm{FE})$ & -0.900387764 & 2.42917867 & 0.16983275 & 0.434274335 \\
\hline $\mathrm{H} 4(\mathrm{FR} \rightarrow \mathrm{HC}$ and FE) & -1.550619184 & 5.548938764 & 0.099795602 & 0.2187788 \\
\hline $\mathrm{H} 5(\mathrm{FR} \rightarrow \mathrm{SC}$ and FE $)$ & -1.230534959 & 5.335780238 & 0.104037588 & 0.306182263 \\
\hline $\mathrm{H} 6(\mathrm{FR} \rightarrow \mathrm{CC}$ and FE $)$ & 0.57812341 & 0.60193250 & 0.4943894 & 0.603721 \\
\hline
\end{tabular}

From all of the above, we can quite unexpectedly conclude that high financial resources do not stimulate the influence of human and structural capital on the efficiency of an enterprise.

\section{Conclusions and Implications}

In this paper, which was based on an electronic questionnaire, empirical data are collected in order to analyze the impact of IC components on the efficiency of SMEs in the transition economies represented by the CIS countries. The purpose of this study was to study the peculiarities of the precepting the problems of managing the intellectual capital of SMEs, as well as to assess the role of its individual elements in maintaining business processes. We assessed the importance of elements of intellectual capital for maintaining a competitive advantage and achieving a certain level of performance in SMEs. As it turned out, the elements of client capital or capital relations that reflect the market potential of SMEs play a special role. In conclusion, we formulated research questions for further surveys in this area.

This study focused on the place of the intangible assets represented here by the intellectual capital as well as its main components (cultural, human, structural, or client) in the process of the company's value creation. According to our results, the tangible assets such as buildings, equipment, and financial assets are no longer the main factors the competitive advantage but can be considered the tools for the growth of an IC of an SME in the context of this study. Notwithstanding, it is the IC that becomes the main driver in the efficient company. In spite of the fact that our hypothesis about the influence of human capital on the efficiency of the organization was fully confirmed, our calculations (conducted with the help of the SPSS statistical package) regarding the influence of financial resources on the indicator of human capital in the structure of IC yielded somewhat unexpected results. According to our opinion, this might be caused by the lack of financial literacy and skills of the managers of SMEs who had limited knowledge of how the financial resources of the companies could be allocated. We think that there might be various reasons for that issue: for example, the quality of labor force, the overall education of the consumers, the investment climate in the country, the existing regulatory framework, as well as some others. Yet, another important factor might be the fact that in CIS countries, administrative and managerial work in most SMEs is carried out directly by the owners and close family members and not by the hired qualified specialists from outside due to an attempt to save a company's internal assets. These findings somewhat differ from those reported in the previous studies and might be of practical interest to managers and SME owners.

Our analysis shows that the relationship between financial resources-client capitalfirm efficiency is directly proportional: an increase in financial investments in client capital invariably leads to an increase in the company's efficiency. The same positive relationship 
can be traced to the relationship between client capital and firm efficiency, albeit with one reservation-in order to increase client capital, tangible financial support might be required.

To conclude, we can state that having analyzed the responses of the respondents to the questions of the online questionnaires, we can state that at present due to the underestimation of intangible assets, many entrepreneurial structures that have a significant number of results of intellectual activity, tend to pay insufficient attention to the development and management of intangible assets and their use to increase competitiveness both in the domestic and foreign markets.

When it comes to the study implications, our results might be interesting for a number of stakeholders. First of all, they are important for business companies, specifically when it comes to budgeting projects aimed at reproducing unique knowledge, implementing procedures for organizing, accounting and planning, financing and investing intellectual capital. The toolkit for the financial assessment of intellectual assets described in our paper can also be used by policymakers in public organizations and non-profit companies as a benchmark for the input of intellectual capital.

Moreover, our study reported the relationship between intellectual assets and business potential. Namely, it presented the intellectual capital of a business as a communicative symbol that can give a signal to those interested in the company and willing to invest in its operation in order to obtain return and profit: investors, managers, creditors, and, most importantly, shareholders.

In addition, our results stemming from our study offer a number of relevant provisions that can guide SME managers when analyzing organizational intellectual capital, intangible assets, and intellectual property. Speaking about the further implications of our study, we believe it also might be relevant and useful as a simulation model for intellectual capital management when making decisions about investments in an organization's intangible assets.

As for the limitations of the study, the first limitation of our study consists of data constraints because of poor official statistics. Therefore, it would be advisable to indicate in any organization the correct structure of human resources, especially regarding personnel with a scientific degree. This disproportion, which is found in the overwhelming majority of enterprises in the CIS, is due to the fact that the ratio between technical personnel and scientific workers is unreasonably low and reduces human potential. The second limitation of our study is the indication of the situation when the presence of capable managers in SMEs is coupled with an absence of team interaction. Such cases often happen but are not easy to track and identify, which might alter the results and lead to distorted conclusions.

Finally, the third limitation of our study is that we used a relatively small sample of representatives of small and medium-sized enterprises from CIS countries. Similar future studies should therefore consider extending the sample. Nevertheless, all these limitations do not diminish the results of our study, which remain both interesting and relevant.

Moreover, let us highlight some pathways and suggestions for future research that may be of interest to researchers in this scientific field. First of all, it might be very useful to conduct an analysis of current trends in approaches to measuring IC and its management accounting in order to highlight key areas that are of fundamental importance for a company's successful operation in the new economy. Second, an interesting subject would the measuring the external influence of IC and its contribution to public welfare. Third, it might be interesting to calculate the expected period of obtaining future benefits from investments in IC both in the transition economies and in the developed economies. Fourth, there is a need to highlight the "strong" and "weak" attributes of intellectual capital, that is, the answer to the question about which measures need to be taken to develop intellectual capital in accordance with the stated strategy of the company.

Author Contributions: Conceptualization, W.S., A.G., U.R., E.K. and A.S.; methodology, W.S., A.G., U.R. and A.S.; validation, U.R. and W.S.; formal analysis, U.R.; investigation, A.G., U.R. and E.K.; resources, E.K. and U.R.; data curation, U.R.; writing-original draft preparation, W.S., A.G., U.R., E.K. and A.S.; writing-review and editing, W.S., A.G., U.R., E.K. and A.S.; visualization, A.G. and 
U.R.; supervision, W.S. and U.R.; project administration, W.S.; funding acquisition, E.K. and A.S. All authors have read and agreed to the published version of the manuscript.

Funding: This research received no external funding.

Institutional Review Board Statement: The study was conducted according to the guidelines of the Declaration of Helsinki, and approved by the Institutional Review Board of Azerbaijan State University of Economics on 20 May 2021.

Informed Consent Statement: Informed consent was obtained from all subjects involved in the study.

Data Availability Statement: Not applicable.

Conflicts of Interest: The authors declare no conflict of interest.

\section{Appendix A}

This appendix presents a questionnaire aimed at finding out the opinions of respondents-heads of SMEs in CIS countries-about the assessment of intellectual capital at an enterprise.

Managers are invited to take part in a study that aims to provide real help in assessing intellectual capital in SMEs in order to improve management efficiency.

List of suggested questions (only one question needs to be answered):

1. Qualification of employees

- High school level

- Bachelor level

- Master's level

- Doctoral thesis level

- PhD level

2. Economics field

- Industry

- Agriculture

- Services

3. Enterprise size

10-20 people

21-50 people

51-100 people

101-150 people

4. Age of the company

$1-10$ years

11-20 years

More than 20 years

5. The level of human capital in your enterprise

- Employees of the enterprise do not need advanced training

- The company is actively involved in improving the qualifications of all rank-andfile employees and management personnel

- The company is actively involved in professional development and is interested in the career growth of employees

- The staff is aware of the strategic goals of the enterprise, is interested in them and actively participates in their achievement

- Expenses related to personnel training are considered as a priority and necessary; the company has a clear strategy in relation to the employment of family members of employees

6. The level of structural capital in your enterprise

- Employee training is needed primarily for the employee himself 
- Employee training is considered with the aim of improving the overall performance of the company

- Employee training is seen as a means of organizational development

- Employee training is seen as a tool to support corporate strategy

7. The level of client capital in your enterprise

- Ordinary employees do not have direct access to the client

- Ordinary employees do not have specific competencies for successful work with a client

- The company's employees have all the skills for effective business communication, customer service, attention to customers and perseverance.

- Most of the company's clients are completely loyal to SMEs for a long time

- The majority of clients spread positive messages and allow the company to increase profits by attracting new customers.

- The number of "regular" customers is greater than the number of "new" and "old" consumers of the firm's products or services

8. Financial resources

- Current financial resources are critically insufficient to maintain the competitive advantage of the organization

- The firm's management is dissatisfied with the company's intangible resource portfolio

- The financial situation in the company is quite stable

- The company has the capacity to launch a new product or service

- The firm has unique competitive advantages through the use of its own financial resources and a unique portfolio of personnel competencies

9. Firm efficiency

- Return on equity

- Return on sales

- Return on investment

- Return on assets

- Sales growth

- Net profitability

\section{References}

1. Absah, Y.; Muchtar, Y.C.; Qamariah, I. Human capital on business performance on distro and boutique SME in Medan City. In Proceedings of the International Conference of Science, Technology, Engineering, Environmental and Ramification Researches; SciTePress: Setúbal, Portugal, 2018; pp. 1570-1573. [CrossRef]

2. Alcaide Muñoz, C.; Ollo López, A.; De La Torre, R. A review of intellectual property management practices using qualitative comparative analysis. Int. J. Intellect. Prop. Manag. 2019, 9, 264. [CrossRef]

3. Arenas, T.; Lavanderos, L. Intellectual capital: Object or process? J. Intellect. Cap. 2008, 9, 77-85. [CrossRef]

4. Banos-Caballero, S.; Garcia-Teruel, P.J.; Martinez-Solano, P. Working capital management in SMEs. Account. Financ. 2010, 50, 511-527. [CrossRef]

5. Barpanda, S.; Mukhopadhyay, S. Intellectual capital components in Indian microfinance SECTOR: Scale development and an empirical study. Int. J. Learn. Intellect. Cap. 2016, 13, 338. [CrossRef]

6. Roos, G.; O'Connor, A. Government policy implications of intellectual capital: An Australian Manufacturing case study. J. Intellect. Cap. 2015, 16, 364-389. [CrossRef]

7. Zakery, A.; Saremi, M.S. Knowledge and intellectual capital in internationalizing SMEs, case study in technology-based health companies. J. Intellect. Cap. 2020, 22, 219-242. [CrossRef]

8. Demartini, M.C.; Beretta, V. Intellectual capital and SMEs' performance: A structured literature review. J. Small Bus. Manag. 2020, 58, 288-332. [CrossRef]

9. Gruzina, Y.; Firsova, I.; Strielkowski, W. Dynamics of Human Capital Development in Economic Development Cycles. Economies 2021, 9, 67. [CrossRef]

10. Popkova, E.G.; Sergi, B.S. Human capital and AI in industry 4.0. Convergence and divergence in social entrepreneurship in Russia. J. Intellect. Cap. 2020, 21, 565-581. [CrossRef] 
11. Popescu, C.R.G.; Popescu, G.N. An exploratory study based on a questionnaire concerning green and sustainable finance, corporate social responsibility, and performance: Evidence from the Romanian business environment. J. Risk Financ. Manag. 2019, 12, 162. [CrossRef]

12. OECD 2020. Quasi-Random Sampling. Available online: https://stats.oecd.org/glossary (accessed on 23 August 2021).

13. Cisi, M.; Centrone, F.A. The Human Capital for Value Creation and Social Impact: The Interpretation of the IR's HC Definition. Sustainability 2021, 13, 6989. [CrossRef]

14. Ullah, I.; Mirza, B.; Jamil, A. The influence of ethical leadership on innovative performance: Modeling the mediating role of intellectual capital. J. Manag. Dev. 2021, 40, 273-292. [CrossRef]

15. Aránega, A.Y.; Núñez, M.T.D.V.; Sánchez, R.C. Mindfulness as an intrapreneurship tool for improving the working environment and self-awareness. J. Bus. Res. 2020, 115, 186-193. [CrossRef]

16. Benevene, P.; Buonomo, I.; Kong, E.; Pansini, M.; Farnese, M.L. Management of Green Intellectual Capital: Evidence-Based Literature Review and Future Directions. Sustainability 2021, 13, 8349. [CrossRef]

17. Khalique, M.; Bontis, N.; Abdul Nassir bin Shaari, J.; Isa, A.H.M. Intellectual capital in small and medium enterprises in Pakistan. J. Intellect. Cap. 2015, 16, 224-238. [CrossRef]

18. Mahmood, T.; Mubarik, M.S. Balancing innovation and exploitation in the fourth industrial revolution: Role of intellectual capital and technology absorptive capacity. Technol. Forecast. Soc. Chang. 2020, 160, 120248. [CrossRef]

19. Lu, Y.; Li, G.; Luo, Z.; Anwar, M.; Zhang, Y. Does intellectual capital spur sustainable competitive advantage and sustainable growth? A study of Chinese and Pakistani firms. Sage Open 2021, 11, 1-18.

20. Leitner, K.-H. Intellectual capital, innovation, and performance: Empirical evidence from SMEs. Int. J. Innov. Manag. 2015, 19, 1550060. [CrossRef]

21. Luederitz, C.; Caniglia, G.; Colbert, B.; Burch, S. How do small business pursue sustainability? The role of collective agency for intergrating planned and emergent strategy making. Bus. Strategy Environ. 2021. [CrossRef]

22. Ben Arfi, W.; Hikkerova, L. Corporate entrepreneurship, product innovation, and knowledge conversion: The role of digital platforms. Small Bus. Econ. 2021, 56, 1191-1204. [CrossRef]

23. Cohen, S.; Naoum, V.-C.; Vlismas, O. Intellectual capital, strategy and financial crisis from a SMEs perspective. J. Intellect. Cap. 2014, 15, 294-315. [CrossRef]

24. Tefera, C.A.; Hunsaker, W.D. Intangible assets and organizational citizenship behavior: A conceptual model. Heliyon 2020, 6, e04497. [CrossRef]

25. Radonić, M.; Vukmirović, V.; Milosavljević, M. The Impact of Hybrid Workplace Models on Intangible Assets: The Case of an Emerging Country. Amfiteatru Econ. 2021, 23, 770-786. [CrossRef]

26. Steenkamp, N.; Kashyap, V. Importance and contribution of intangible assets: SME managers' perceptions. J. Intellect. Cap. 2010, 11, 368-390. [CrossRef]

27. Lopus, J.S.; Amidjono, D.S.; Grimes, P.W. Improving financial literacy of the poor and vulnerable in Indonesia: An empirical analysis. Int. Rev. Econ. Educ. 2019, 32, 100168. [CrossRef]

28. Dorofeev, V.D.; Dresvyannikov, V.A.; Taktarova, S.V. Perception intelligence as an element of human intellectual capital and its assessment among university students. Int. J. Learn. Intellect. Cap. 2018, 16, 60-86. [CrossRef]

29. Lacroix, J.; Vidal-Coso, E. Differences in labor supply by birthplace and family composition in Switzerland: The role of human capital and household income. J. Int. Migr. Integr. 2018, 20, 659-684. [CrossRef]

30. Qin, C.; Chen, C. The development of high-tech industries in Guangdong province: Based on dynamic Shift share analysis. In Proceedings of the 2nd International Conference on Artificial Intelligence, Management Science and Electronic Commerce (AIMSEC), Dengfeng, China, 8-10 August 2011; pp. 5886-5889. [CrossRef]

31. Gupta, O. Managing Intellectual Capital in Practice; Routledge: London, UK, 2007; Volume 11, pp. 83-84. [CrossRef]

32. Gwak, M. The knowledge level of Insurance consumers and its influential factors. Consum. Policy Educ. Rev. 2019, 15, 105-127. [CrossRef]

33. Ryabinin, E.V.; Hudorenko, E.A. Improving methods estimation of the investment climate of the country. Stat. Econ. 2016, 5, 18-22. [CrossRef]

34. Saimova, S.; Khairmukhanmedov, N.; Syrlybayev, M. Constitutional-legal framework of interethnic relations in Kazakhstan. PONTE Int. Sci. Res. J. 2016, 72, 1-10. [CrossRef]

35. Korotun, O. The role of public authorities in the protection and protection of intellectual property rights. Leg. Nov. 2019, 9, 92-98. [CrossRef]

36. Giuliani, M. Intellectual capital under the temporal lens. J. Intellect. Cap. 2009, 10, 246-259. [CrossRef]

37. Menna, A.R.; Walsh, P.; Ekhtari, H. Identifying enablers of innovation in developed economies: A national Innovation systems approach. J. Innov. Manag. 2019, 7, 108-128. [CrossRef]

38. Hong, J.; Lu, J. Assessing the effectiveness of business incubators in fostering SMEs: Evidence from China. Int. J. Entrep. Innov. Manag. 2016, 20, 45-60. [CrossRef]

39. Stewart, T.A. The Wealth of Knowledge: Intellectual Capital and the Twenty-First Century Organization; Doubleday: New York, NY, USA, 2003.

40. Barpanda, S.; Mukhopadhyay, S. Does firmography patterns human resource practice? Evidence from microfinance industry of India. Asian J. Empir. Res. 2020, 10, 24-39. [CrossRef] 
41. Nerdrum, L.; Erikson, T. Intellectual capital: A human capital perspective. J. Intellect. Cap. 2001, 2, 127-135. [CrossRef]

42. Jardon, C.M. The use of intellectual capital to obtain competitive advantages in regional small and medium enterprises. Knowl. Manag. Res. Pract. 2015, 13, 486-496. [CrossRef]

43. Henry, L. Intellectual capital in a recession: Evidence from UK SMEs. J. Intellect. Cap. 2013, 14, 84-101. [CrossRef]

44. Samad, S. Assessing the contribution of human capital on business performance. Int. J. Trade Econ. Financ. 2013, 4, 393. [CrossRef]

45. Chigoryaev, K.N.; Skopintseva, N.A.; Ulyashchenko, V.V. Estimation of the cost of human capital on the basis of produced costs. Bull. Tomsk. Polytech. Univ. 2008, 313, 54-56.

46. Postrelova, A.V.; Donskova, M.V. Assessment of the intellectual capital of the enterprise. In Problems and Prospects of Economics and Management. Proceedings of the 2nd International Scientific Conference, Saint Petersburg, Russia, 20-23 June 2013; Ulyanovsk State Technical University Press: Ulyanovsk, Russia, 2013.

47. Berger, P.D.; Nasr, N.I. Customer lifetime value: Marketing models and applications. J. Interact. Mark. 1998, 12, 17-30. [CrossRef]

48. Petrov, V.G.; Polunovskiy, A.A.; Sokolyanskiy, V.V. Modeling of intellectual capital of the organization on the basis of Markov chains. J. Creat. Econ. 2017, 6, 707-724.

49. Cauchie, G.; Vaillant, N.G. New firm survival: Isolating the role of founders' human capital in accounting for firm longevity. J. Hum. Cap. 2016, 10, 186-211. [CrossRef]

50. Mathuva, D.M. An empirical analysis of the determinants of the cash conversion cycle in Kenyan listed non-financial firms. J. Account. Emerg. Econ. 2014, 4, 175-196. [CrossRef]

51. Tran, N.P.; Vo, D.H. Do banks accumulate a higher level of intellectual capital? Evidence from an emerging market. J. Intellect. Cap. 2020. [CrossRef]

52. Podsakoff, P.M.; MacKenzie, S.B.; Lee, J.-Y. Common Method Bias in Behavioral Research: A Critical Review of the Literature and Recommended Remedies. J. Appl. Psychol. 2003, 88, 879-903. [CrossRef]

53. Werts, C.E.; Linn, R.L. Path analysis: Psychological examples. Psychol. Bull. 1970, 74, 193-212. [CrossRef] 